Kerry B. Bernes and Angela D. Bardick are registered psychologists with the University of Lethbridge, Lethbridge, Alberta, Canada. E-mail: abardick@shaw.ca

\title{
Conducting Adolescent Violence Risk Assessments: A Framework for School Counselors
}

There have been numerous publications devoted to preventing violence and bullying in schools, resulting in school counselors being well equipped with school-wide violence prevention ideas and programs. Despite these violence prevention efforts, some students may pose a threat to others and thus may require a comprehensive assessment for violence risk, especially targeted violence. The purpose of this article is to provide school counselors with a framework for assessing students who may be at risk for violence in general or who may be at risk specifically for targeted violence.

Contin ome shocking acts of adolescent violence have brought significant attention to the role that school counselors have in preventing such incidents of violence. Consequently, school counseling journals have published a significant number of articles devoted to assessment and interventions for bullying (Crothers \& Levinson, 2004; Elinoff, Chafouleas, \& Sassu, 2004; Newman-Carlson \& Horne, 2004), behavioral disorders (Frick, 2004; Olympia, Farley, Christiansen, Pettersson, \& Clark, 2004), violence potential (Burns, Dean, \& JacobTimm, 2001), psychopathy in youth (Gacono \& Hughes, 2004), conflict resolution (Brinson, Kottler, \& Fisher, 2004), and the role of school counselors in school violence prevention and intervention (Canfield, Ballard, Osmon, \& McCune, 2004; Cunningham \& Sandhu, 2000; D'Andrea, 2004; Hernández \& Seem, 2004; Lapan, Gysbers, \& Petroski, 2001; Riley, 2000; Rollin, Kaiser-Ulrey, Potts, \& Creason, 2003; Schaefer-Schiumo \& Ginsberg, 2003; Smith \& Sandhu, 2004; Stanley, Juhnke, \& Purkey, 2004). The majority of the recommendations for school counselors focus on prevention and intervention, with brief statements about identifying early warning signs of violence or making a referral for assessment.

Despite prevention efforts, some students may pose a serious threat to harm others and thus may require a comprehensive assessment of violence risk. As counselors become more aware of their role in preventing and intervening in school violence as well as the importance of engaging in evidence-based practice (Borum, Fein, Vossekuil, \& Berglund, 1999; Borum \& Reddy, 2001; Burns et al., 2001; Olympia et al., 2004), the need for school counselors to conduct comprehensive assessments of violence risk in adolescents becomes more apparent. We are not advocating that school counselors assess every student on their caseload for violence potential; however, should a situation arise in which an assessment of violence risk is needed, the framework for violence risk assessment provided in this article may be helpful.

Hermann and Finn (2002) published an excellent article in Professional School Counseling entitled "An Ethical and Legal Perspective on the Role of School Counselors in Preventing Violence in Schools." They stated that school counselors have not yet been held liable for not accurately assessing the potential for school violence. Hermann and Finn recommended that school counselors keep up to date on effective risk assessment techniques in order to ensure that they are knowledgeable on the current state of the field. Staying current with regard to violence risk assessment knowledge helps school counselors to make informed decisions as to the risk level of a particular individual student. It also helps to ensure that the school counselor has met the standard of care of the field. In other words, if a court were to try to determine if a school counselor should be held liable for inaccurately assessing a student for the potential for violence, a comparison would need to be made between the procedures followed by the school counselor conducting the assessment and the standard of care generally accepted by the field, in this case the field of adolescent violence risk assessment.

Staying current with adolescent violence risk assessment and moving beyond Hermann and Finn's (2002) recommendations would require school counselors to become familiar with assessment instruments such as the Structured Assessment of Violence Risk in Youth (SAVRY; Borum, Bartel, \& Forth, 2003) and the notion of targeted violence 
risk assessments (Borum \& Reddy, 2001). The purpose of this article is to update school counselors on the current state of practice in adolescent violence risk assessment by providing an overview of the current understanding of school violence, the evolution of assessment of violence risk, as well as descriptions of the SAVRY and targeted violence risk assessments.

\section{ASSESSMENT OF VIOLENCE RISK}

Despite the limited number of actual severe violent behaviors in the form of school shootings, the risk for any type of violent behavior exists in all schools. School violence may range on a continuum from subtle behaviors (e.g., teasing, name calling, bully-

\section{Staying current} with regard to violence risk knowledge helps school counselors to make informed decisions as to the risk level of a particular individual student. assessment ing, and other forms of intimidation and harassment) to severe actions, such as physical fights and shootings (Hernández \& Seem, 2004; Smith \& Sandhu, 2004). Hazler, Hoover, and Oliver (1996) reported that three out of four of the students they surveyed reported experiencing academic, personal, and social difficulties due to bullying and harassment. Students who experience harassment and bullying may experience threats to their emerging identity, which may increase feelings of powerlessness and hostility and thus contribute to a desire for revenge that escalates into a violent episode (Hazler, 2000). D'Andrea (2004) proposed the following six categories of violence: (a) physical violence, (b) sexual and gender violence, (c) media violence, (d) cultural-racial violence, (e) political-economic violence, and $(f)$ violence of silence. A broad definition of violence ranging from mild to severe underscores the importance of comprehensive assessment to determine the level of risk and thus inform intervention programs.

The first-generation violence risk assessments were conducted by clinical judgment or clinical wisdom. In other words, professionals first began to make assessments for the potential for violence on the basis of nothing other than their own experience. Such assessments (even when done by professionally trained psychiatrists, psychologists, or counselors) were not found to be any more effective than judgments made by people without any training in the field of counseling, psychology, medicine, or psychiatry (Burns et al., 2001; Reddy et al., 2001). Early risk assessments may have included early warning sign lists to assist with clinical judgment; however, Burns et al. reported that there is "little to no information regarding the reliability or validity of such lists ... there are no informal checklists that can accurately identify pupils who will commit violent acts" (p. 241-242). Such informal assessments may result in the over-identification of students at risk for committing a violent act (Burns et al.).

To improve on the predictive ability of violence risk assessments, the field evolved to what has become known as the second generation of violence risk assessments, actuarial risk assessments (Borum et al., 2003). Actuarial risk assessments sought to place numerical predictions on the risk for potential violence. The problem with actuarial assessments was that they required professionals conducting the assessment to stick rigidly to numerical rating systems designed to determine mathematical predictions on the potential for violence. The professional had to stay with the mathematically derived formula designed to measure the potential for violence even if some factors may have been more individually relevant to a particular assessment. This left the professional with very little clinical judgment to account for unique circumstances within a particular assessment. Another limitation was that there has been no empirical research on risk factors for targeted school violence, and empirical research on general violence recidivism has limited bearing on targeted school violence (Reddy et al., 2001). Thus, actuarial assessments relying on empirical risk factors might lead to an underestimation of risk (Borum \& Reddy, 2001). Actuarial risk assessments also placed emphasis on static and historical risk factors, which do not account for the dynamic nature of violence risk in adolescents.

The third generation of violence risk assessment procedures is known as structured professional judgment (Borum et al., 2003). The structured professional judgment framework was developed by examining the research on the factors that have been found to be linked to the likelihood of an increased risk for violence (Borum et al.). Such factors then were organized into user-friendly manuals for use by counselors, social workers, psychologists, and psychiatrists for conducting violence risk assessments. Guiding principles for structured professional judgment in violence risk assessment are as follows: (a) There is no profile or single "type" of perpetrator of targeted violence; (b) there is a dynamic interaction among perpetrator, situation, target, and the setting; (c) there is a distinction between making a threat (expressing an intent to harm a target to the target or others) and posing a threat (engaging in behaviors that lead to a plan to harm); and (d) targeted violence is not random or spontaneous (Reddy et al., 2001).

There is extensive literature on the risk factors for violence and aggression in adolescents (see Borum, 2000; Hazler, 2000; Vossekuil, Reddy, Fein, Borum, \& Modzeleski, 2000). Although risk factors are not predictive of violence, risk factors increase the possibility that an individual will become violent, and multiple risk factors further increase that possibility (Hermann \& Finn, 2002). The following list of risk factors is by no means exhaustive of the many possible factors that may contribute to adolescent vio- 
lence. It is meant to alert the reader to the complexity and range of interacting risk factors associated with adolescent violence, thus necessitating the need for risk assessments to move beyond clinical judgment and actuarial approaches.

Risk factors include biological, psychological, cognitive, and environmental risk factors (Hazler, 2000). The rapid psychological and physiological changes during puberty make puberty itself a biological risk factor (Hazler). Psychological risk factors include adolescent depression (Hazler; Latzman \& Swisher, 2005), conduct disorder (Frick, 2004; Gacono \& Hughes, 2004), and substance use (Makinson \& Meyers, 2003; Schaefer-Schiumo \& Ginsberg, 2003). Psychopathy is another important concept to consider in violence risk assessments (Gacono \& Hughes). Psychopathy is defined by behaviors associated with conduct disorder (e.g., repeatedly violating the basic rights of others, specifically with aggression to people and animals, destruction of property, deceitfulness or theft, and/or serious violation of rules; American Psychiatric Association, 2000) in addition to specific interpersonal traits (e.g., grandiosity, callousness, arrogance, dominance, superficiality, and manipulation) and affective traits (e.g., short temper, inability to form emotional bonds with others, and lack of guilt or anxiety) (Hare, 1999).

However, it is important to note that a student does not need to be suffering from a diagnosable mental illness to be at risk for committing a violent act. Instead, violent episodes are frequently initiated following incidents of recent losses (Hermann \& Finn, 2002; Sawyer \& Cameron, 2001) or incidents such as bullying (Vossekuil et al., 2000), harassment (Hazler, 2000), alienation (Glasser, 2000), and/or peer rejection (Hermann \& Finn). Feelings correlated with suicidal ideation and attempts - such as humiliation, helplessness, hopelessness, and self-pity (Hazler) - also may be associated with violent behavior. Osher and Warger (1998) found that extreme feelings of isolation and social withdrawal were also common signs of potential violent behavior.

Environmental risk factors, such as role modeling of violent behaviors in the home, school, or community, are also important to consider (Furlong, Morrison, Chung, Bates, \& Morrison, 1997). The home environment may not foster independence or assertiveness, and it may contribute to poor problem-solving abilities (Hazler, 2000). A family history of criminal violence (Moffitt, 1997) as well as childhood sexual, physical, or emotional abuse (James \& Gilliland, 2001) also may increase the risk for violent behavior. The school environment also may increase the risk for violence (Hernández \& Seem, 2004), if there is insufficient adult supervision, tolerance of bullying and teasing, special privi- leges given to certain populations (e.g., honor students or athletes), little access to intervention, ignored threats of violence (Stevens, Lynm, \& Glass, 2001), or ambiguous consequences, low teacher morale, and high student disorder (Sherman et al., 1997). The community also may contribute to increased risk for violence, with social disorganization and overcrowded neighborhoods with high crime rates (Hawkins et al., 1998) and high rates of drug and alcohol use (Schaefer-Schiumo \& Ginsberg, 2003).

Risk factors also revolve around behaviors directly related to threats of violence (e.g., attempting to gain access to weapons, writing about suicide or homicide, or telling someone about their plan; Vossekuil et al., 2000) and warning signs of violent behavior (e.g., harm to small animals or an excessive interest in violent entertainment; Hermann \& Finn, 2002). As can be seen, there are a vast number of risk factors associated with violence in adolescence, thus indicating a need for comprehensive violence risk assessment.

Risk factors to consider when using structured professional judgment in violence risk assessment include historical factors (e.g., previous violence, young age at first violent incident, relationship instability, employment problems, substance use problems, and early maladjustment), clinical and situational factors (e.g., lack of insight, negative attitudes, active symptoms of major mental illness, impulsivity, and unresponsiveness to treatment), and risk management factors (e.g., feasibility of plans, exposure to destabilizers, lack of personal support, noncompliance with remediation, and stress) (Webster, Douglas, Eaves, \& Hart, 1997). Assessment of violence risk in adolescents also requires an emphasis on dynamic and contextual risk factors (e.g., peer delinquency, peer rejection, poor parental management, and community disorganization; Borum et al., 2003). Frick (2004) stated that "the number of risk factors present is more important than the type of risk factor" (p. 824). Thus, the accumulation of risk factors as well as the interactive and dynamic nature of risk factors must be considered.

The presence or absence of youth assets (Aspy et al., 2004) and protective factors (Borum et al., 2003 ) is important to consider in the reduction of violence and aggression risk factors. For example, Aspy et al. found that youth who possessed assets such as family communication and making responsible choices were significantly more likely to report no physical fighting or weapon carrying. As well, students who reported being in high school, living with both parents, and having a higher family income also were associated with no fighting (Aspy et al.). Positive peer relations and engaging in prosocial behaviors buffer negative effects of delinquency and aggression (Caprara, Barbarelli, \& Pastorelli, 2001).
Despite the limited

number of actual

severe violent

behaviors in the

form of school

shootings, the risk

for any type of

violent behavior

exists in all schools. 
Social support (Dubow \& Reid, 1994) and strong attachments with prosocial adults who are supportive and accepting (Simons, Paternite, \& Shore, $2001)$ contribute to resiliency in children.

Personality traits associated with increased resiliency in children include above-average intellectual skills, conflict management skills, positive response to others, adaptability to change, capacity to selfsoothe or be soothed by others, calm mood, and healthy self-esteem (Kumpfer, 1999). Strong commitment to one's school also has been linked to decreased risk of violence (Hawkins et al., 1998). Thus, just as a higher number of risk factors contributes to increased risk for violence, a higher number of protective factors contributes to reduced risk for violence.

A structured professional judgment approach to violence risk assessment involves gathering informa-

Although risk

factors are not

predictive of

violence, risk

factors increase the

possibility that an

individual will

become violent,

and multiple risk

factors further

increase that

possibility. tion about the number of risk factors an individual may have with an emphasis on corroboration of facts and a focus on the progression of attack-related behaviors (Borum \& Reddy, 2001; Reddy et al., 2001). Unlike actuarial risk assessments, assessments using structured professional judgment do not yield a final predictive numerical score. Instead, they lead the professional through a structured list of factors, based on empirical research, to rate throughout the assessment in order to determine a final rating of risk (mild, moderate, or severe). Going back to Hermann and Finn's (2002) work, using a structured approach to risk assessment is critical because establishing liability for inaccurately assessing risk for violence without using structured methods and criteria will increasingly leave school counselors in a vulnerable position if asked how they determined the level of risk in a particular student. Unstructured approaches have the potential for misjudgments, inaccurate assessments, and legal implications if the school counselor's assessment is not based on commonly accepted standards and an appropriate structured approach to the assessment of violence risk (Reddy et al.).

The American School Counselor Association (ASCA, 2004) recommends that school counselors "utilize assessment measures within the scope of practice for school counselors" (p. 2). Structured risk assessment manuals are available for use with adult, adolescent, and child populations. The Historical, Clinical, and Risk Management-20, Version 2 (HCR-20; Webster et al., 1997) and the SAVRY (Borum et al., 2003) are both known as third-generation violence risk assessment procedures based in structured professional judgment. The HCR-20 (Douglas, Webster, Hart, Eaves, \& Ogloff, 2001) was designed for male and female adults. The SAVRY (Borum et al., 2003) was designed for male and female adolescents ages 13 to 17. The Early
Assessment Risk List for Boys (EARL-20B; Augimeri, Koegl, Webster, \& Levene, 2001) and the Early Assessment Risk List for Girls (EARL-21G; Levene et al., 2001) were designed for children 12 and under.

The SAVRY, HCR-20, and EARL-20B and EARL-21G manuals are meant to be used as guides to risk assessment and are not formal psychological tests. Use of the SAVRY may aid school counselors in determining an adolescent's level of risk and thus following the ASCA Ethical Standards for School Counselors in "[informing] parents/guardians or appropriate authorities when the student's condition indicates a clear and imminent danger to the student or others" (ASCA, 2004, p. 2). A description of the SAVRY is provided to inform school counselors of a structured violence risk assessment approach for adolescents.

\section{The SAVRY}

The purpose of the SAVRY (Borum et al., 2003) is to assess risk factors to aid in prevention and risk reduction. The SAVRY consists of four sections (Historical Risk Factors, Social/Contextual Risk Factors, Individual Risk Factors, and Protective Factors). Each section lists specific factors the assessor should consider in making a general assessment for the risk of potential violence. Information to code the items should be obtained from multiple sources, including youth self-report, parental/caregiver reports, teacher reports, social worker reports, police reports, previous psychological and/or psychiatric evaluations, school records, juvenile justice records, and mental health and/or medical records (Borum et al., 2003). The credibility of the informant should be carefully considered, and with more weight being placed on the most credible sources (Borum et al.). Cross-checking information is important for verification (Cormier, 1994).

There is limited research pertaining to the reliability and validity of the SAVRY because the SAVRY has only been available since 2003 and instruments used in structured professional judgment "are not numerically driven," thus creating challenges for determining statistical validity and reliability (Bartel, Borum, \& Forth, 2005). However, the initial validation samples found an internal consistency of .82 for offenders and .84 for the community sample for the SAVRY risk total (Bartel et al.). Catchpole and Gretton (2003) and McEachran (2001) found similar interrater reliability scores, .81 and .83 for the SAVRY total score and .77 and .72 for the summary risk rating, respectively. In the initial validation study (Bartel et al.), the SAVRY was found to correlate significantly with the Youth Level of Service/Case Management Inventory (Hoge \& Andrews, 2002) and the Hare Psychopathy 
Checklist: Youth Version (Forth, Kosson, \& Hare, 2003). More research on the reliability and validity of the SAVRY is needed.

\section{Description of the SAVRY Risk Factors}

Historical risk factors. Historical items are based on past experiences and behavior. They are generally static, and they have been shown to be associated with violence risk in adolescence. The historical items included in the SAVRY are (a) history of violence, (b) history of nonviolent offending, (c) early initiation of violence, (d) past supervision/intervention failures, (e) history of self-harm or suicide attempts, (f) exposure to violence in the home, $(\mathrm{g})$ childhood history of maltreatment, (h) parental/ caregiver criminality, (i) early caregiver disruption, and (j) poor school achievement.

Each of the above historical items is coded as low, moderate, or high. The manual provides explicit directions for what constitutes a rating of low, moderate, or high for each item. For example, under "history of violence," the manual specifies that a low rating would apply to an adolescent who has not committed any acts of violence in the past, a moderate rating would apply to an adolescent who has committed one or two acts of violence, and a high rating would apply to an adolescent who has committed three or more acts of violence (Borum et al., 2003). The manual also specifies that each of the constructs be considered in making a thorough assessment. With regard to history of violence, for example, the manual defines violence as an

act of battery or physical violence that is sufficiently severe to cause injury to another person or persons (i.e., cuts, bruises, broken bones, death, etc.), regardless of whether injury actually occurs; any act of sexual assault; or threat made with a weapon in hand.

(Borum et al., p. 23)

Excluded from the definition are "minor acts of aggression that do not have a reasonable likelihood of resulting in injury (e.g., sibling wrestling, light hair pulling)" (Borum et al., p. 23).

Social/contextual risk factors. The influences of peer and family relationships, connection to social institutions, and environment are important to consider in adolescent risk assessment. The social/contextual risk factors in the SAVRY are (a) peer delinquency, (b) peer rejection, (c) stress and poor coping, (d) poor parental management, (e) lack of personal/social support, and (f) community disorganization. Similar to the historical risk factors, the social/contextual risk factors are coded as low, moderate, or high. Descriptors of each also are included in the manual.
Individual risk factors. Youth attitudes and psychological and behavioral functioning also are included in the SAVRY. Individual risk factors include (a) negative attitudes, (b) risk taking/impulsivity, (c) substance use difficulties, (d) anger management problems, (e) low empathy/remorse, (f) attention deficit/hyperactivity difficulties, (g) poor compliance, and (h) low interest/commitment to school. Each of the above individual risk factors is coded as low, moderate, or high with applicable descriptors found within the manual.

Protective factors. Risk factors increase the likelihood of violence, while protective factors may reduce the overall potential for violence. Protective factors include (a) prosocial involvement, (b) strong social support, (c) strong attachments and bonds, (d) positive attitude toward intervention and authority, (e) strong commitment to school, and (f) resilient personality traits. Protective factors are simply rated as present or absent.

A thorough understanding of and supervision in utilizing the SAVRY is a necessary component when evaluating the general risk factors that may need to be considered in assessing an adolescent for the potential of violence; however, another critical and sometimes even more imminent portion of the assessment may be the assessment for targeted violence.

\section{TARGETED VIOLENCE RISK ASSESSMENT}

Targeted violence risk assessments are very similar to what school counselors have been trained in with regard to suicide assessments. In the case of suicide, the central questions revolve around suicidal ideation, plans, mood disorders (i.e., depression), substance use disorders, hopelessness (U.S. Preventive Services Task Force, 2004), intention to die, and lethality (Capuzzi, 2002). Information obtained from a suicide assessment leads the school counselor to a determination of the degree of risk and targets for intervention (e.g., taking away the means, contracting, counseling, hospitalization; Capuzzi). Similarly, the central questions in the case of targeted violence risk assessments revolve around whether the student is "on a pathway toward a violent act and if so how fast he or she is moving and where could one intervene?" (Borum \& Reddy, 2001, p. 377).

As noted by previous researchers (Stevens et al., 2001; Vossekuil et al., 2000), incidents of school violence usually are planned. Such planning includes what Borum and Reddy (2001) called attackrelated behaviors.

[Attack-related behaviors] may include developing an idea and plan to engage in a violent act toward a target; acquiring the means or

\section{An individual violence risk \\ assessment may \\ lead to increased \\ awareness of \\ environmental risk \\ factors that then \\ may be targeted \\ using school-wide \\ or community-wide \\ prevention \\ programs.}


capacity for the violent act (such as a weapon or other means of inflicting harm); selecting a target or targets; and determining the time, place, and manner in which to approach or otherwise gain access to the target (such as discovering the target's [schedule of activities]). These behaviors indicate planning and preparation for an attack. They are significant markers of the client's movement on the pathway from idea to action. (p. 380)

Given the idea that planning usually precedes acts of violence, Borum and Reddy (2001) developed an acronym, ACTION, to guide professionals to consider six areas of inquiry when conducting targeted violence risk assessments. ACTION stands for (a) Attitudes that support or facilitate violence, (b) An assessmentCapacity, (c) Thresholds crossed, (d) Intent, (e Others' reactions and responses, and (f) Noncompliance with risk reduction interventions.

Attitudes that support or facilitate violence may be summarized by seeking to understand if the student believes that the use of violence is justified under certain circumstances. Obviously, the more the student believes he or she is justified and that violence is necessary, the greater the risk (Borum \& Reddy, 2001). It is important to routinely ask screening questions about violent behavior, such as the following: (a) Have you hit people or damaged things when you are angry? (b) Do you worry that you might physically hurt someone? (c) Has there been a time when you have hurt someone (e.g., kicking, hitting, slapping, pushing, shoving, or grabbing)? (d) Have you ever threatened anyone with a weapon? (Borum, 2000). If the response to the screening questions is positive, then further inquiry into the nature of the violent behavior is required.

In terms of Capacity, the central question revolves around whether the student has the capacity or means to carry out the type of violent act that he or she has threatened. This includes the physical and intellectual capabilities, access to means (weapons or materials necessary to follow through with the violent act), access to the target(s), and opportunity to commit the act (Borum \& Reddy, 2001).

Thresholds crossed refers to the steps the student has followed in order to enact the plan, such as any attack-related behaviors or any behaviors that require breaking laws and/or school rules (Borum \& Reddy, 2001).

Intent refers to the distinctions between thoughts and intentions to commit the act. Questions to focus on include the following: (a) Does the student have thoughts or intentions to commit a violent act? (b) How specific is the plan? (c) Is he or she making any movement to acquiring the means? (d) Does the student believe that he or she has no other available options or that he or she has nothing to lose? (Borum \& Reddv, 2001). School counselors trained in suicide assessment and intervention will be noting the similarities between suicide and violence risk assessments.

Others' reactions and responses focus the school counselor on inquiring about how other individuals have responded to the student's plans. Questions to consider include the following: (a) Has the student communicated with anyone about his or her plans for violence? (b) How does the student report that others have responded? (c) Have others discouraged, condemned the ideas, offered no judgment, supported or escalated the violent ideas, or even facilitated the movement from idea to action? (d) Are others concerned that the student may do it? (Borum \& Reddy, 2001). Answering these questions, in fact answering many of the questions from the SAVRY and questions revolving around targeted violence risk assessments, will require the school counselor to obtain third-party information from others who may be able to substantiate or further inform the assessment process. Such third-party sources may include peers, parents, teachers, police officers, probation officers, physicians, psychiatrists, psychologists, social workers, and any other people who may have knowledge of the student and the circumstances involved. The use of third-party data from collateral interviews and a review of applicable documentation are critical to comprehensive violence risk assessment.

Noncompliance with risk reduction interventions is the sixth area of inquiry to be assessed in Borum and Reddy's (2001) ACTION acronym. Questions to consider here include the following: (a) Is the student motivated to prevent or avoid a violent act? (b) Is the student willing to participate in interventions to reduce or mitigate risk? (c) Does the student have a history of complying with risk reduction efforts? (d) Does the student possess enough insight to understand or appreciate the severity of his or her own disorder (if one exists), need for treatment, and/or potential for violence? (Borum \& Reddy).

\section{IMPLICATIONS FOR PROFESSIONAL SCHOOL COUNSELORS}

Intervening in adolescent violence begins with a comprehensive assessment. The current standards for violence risk assessment in adolescents include using structured professional judgment, which involves using the SAVRY and a targeted violence risk assessment model (Borum \& Reddy, 2001). Use of the SAVRY allows the school counselor to examine general risks for violence, and use of the targeted violence risk assessment model, specifically the ACTION acronym (Borum \& Reddy), allows the 
school counselor to examine specific risks for targeted violence. Within the structured professional judgment model, the continuum of violence risks is assessed, ranging from subtle to overt forms of violence. An examination of the historical, social/contextual, individual, and protective factors in the SAVRY combined with specific assessment for targeted violence creates a very comprehensive assessment that can be used to direct interventions. Following are examples of how the SAVRY may be used to direct interventions.

It is important to note that historical risk factors, social/contextual risk factors, individual risk factors, and protective factors in the SAVRY not only inform a thorough assessment for the potential for violence, but they also highlight areas in need of intervention. Each risk factor may become a focus for intervention, with an assessment of all risk factors informing a comprehensive, individualized treatment program. Although an individual's history cannot be changed, some historical risk factors contributing to violence risk may be addressed. For example, exposure to violence in the home and childhood history of maltreatment may be addressed by involving child welfare to prevent future harm in addition to obtaining appropriate individual and/or family counseling. Early caregiver disruption may be identified as a risk factor, which may become a focus for individual and/or family counseling. Poor school achievement may be further assessed with a psycho-educational assessment, which then may be used to implement appropriate school program planning.

A number of social/contextual items may become a focus for intervention. For example, peer delinquency, peer rejection, and lack of personal/social support as identified risk factors inform the development of a treatment plan that focuses on developing stronger relationships with prosocial peers and adults. Stress and poor coping may be addressed with problem-solving skills training and counseling. Poor parental management as a risk factor may inform goals for family counseling and/or parental skills training interventions.

Additionally, an individual violence risk assessment may lead to increased awareness of environmental risk factors (e.g., community disorganization) that then may be targeted using school-wide or community-wide prevention programs. Individual risk factors, such as substance use difficulties and anger management problems, become individual targets for intervention. Protective factors, such as prosocial involvement, strong attachments and bonds, and resilient personality traits, are also important to consider when designing an intervention program. The absence of any protective factor becomes an important target for intervention.

As can be seen by these examples, a thorough con- sideration of each of the factors in the SAVRY significantly informs both the assessment and intervention processes, thereby minimizing the likelihood of being found liable for conducting inadequate or incompetent violence risk assessments and failing to take the necessary precautions for reducing the risk of violence. Interventions may require a multidisciplinary team and may, therefore, involve the school counselor in working with the student, parents, psychologists, psychiatrists, addiction treatment programs, and/or other external resources that may be deemed necessary to reduce the risk. An assessmentdriven approach to intervention also may result in increasing the effectiveness of existing programs by more systematically "determining which children are most likely to benefit from them" (Frick, 2004, p. 830).

Careful assessment, thorough documentation, and professional consultation (Ash, 2002) are highly recommended to provide protection from malpractice claims in the case of adolescent violence. School counselors are responsible for documenting all risk assessment procedures used, information gathered from any and all sources, and how the risk factors were considered in making clinical decisions and designing treatment plans (Wingate, Joiner, Walker, Rudd, \& Jobes, 2004). Consultation with professionals trained in the field of violence risk assessment is valuable to improve the accuracy of risk estimation (Packman, Marlitt, Bongar, \& O'Connor Penuto, 2004).

With this article providing school counselors with an update of the best practices for violence risk assessment in adolescents, school counselors should now be better equipped to assess violence risk in their schools, thereby meeting the current standard of care, minimizing liability concerns, and informing interventions. A comprehensive assessment of violence risk is an important component of school violence prevention and intervention.

\section{References}

American Psychiatric Association. (2000). Diagnostic and statistical manual of mental disorders (4th ed., text rev.). Washington, DC: Author.

American School Counselor Association. (2004). Ethical standards for school counselors. Retrieved August 11, 2005, from http://www.schoolcounselor.org/files/ ethical\%20standards.pdf

Ash, P. (2002). Malpractice in child and adolescent psychiatry. Child and Adolescent Psychiatric Clinics of North America, 11, 869-885.

Aspy, C. B., Oman, R. F., Vesely, S. K., McLeroy, K., Rodine, S., \& Marshall, L. (2004). Adolescent violence: The protective effects of youth assets. Journal of Counseling \& Development, 82, 268-276.

Augimeri, L. K., Koegl, C. J., Webster, C. D., \& Levene, K. (2001). Early assessment risk list for boys, version 2. Toronto, Ontario, Canada: Earlscourt Child and Family Center. 
Bartel, F., Borum, R., \& Forth, A. (2005). SAVRY research. Retrieved August 11, 2005, from http://www.fmhi.usf. edu/mhlp/savry/SAVRY_Research.htm

Borum, R. (2000). Assessing violence risk among youth. Journal of Clinical Psychology, 56, 1263-1288.

Borum, R., Bartel, F., \& Forth, A. (2003). Manual for the structured assessment of violence risk in youth. Tampa, FL: University of South Florida.

Borum, R., Fein, R., Vossekuil, B., \& Berglund, J. (1999). Threat assessment: Defining an approach for evaluating risk of targeted violence. Behavioral Sciences and the Law, 17, 323-337.

Borum, R., \& Reddy, M. (2001). Assessing violence risk in Tarasoff situations: A fact-based model of inquiry. Behavioral Sciences and the Law, 19, 375-385.

Brinson, J. A., Kottler, J. A., \& Fisher, T. A. (2004). Cross-cultural conflict resolution in the schools: Some practical intervention strategies for counselors. Journal of Counseling \& Development, 82, 294-301.

Burns, M. K., Dean, V. J., \& Jacob-Timm, S. (2001). Assessment of violence potential among school children: Beyond profiling. Psychology in the Schools, 38, 239-246.

Canfield, B. S., Ballard, M. B., Osmon, B. C., \& McCune, C. (2004). School and family counselors work together to reduce fighting at school. Professional School Counseling, 8 , 40-46.

Caprara, G. V., Barbarelli, C., \& Pastorelli, C. (2001). Prosocial behavior and aggression in childhood and preadolescence. In A. Bohart \& D. Stipek (Eds.), Constructive and deconstructive behavior: Implications for family, school, and society (pp. 187-204). Washington, DC: American Psychological Association.

Capuzzi, D. (2002). Legal and ethical challenges in counseling suicidal students. Professional School Counseling, 6, 36-45.

Catchpole, R., \& Gretton, H. (2003). The predictive validity of risk assessment with violent young offenders: A 1-year examination of criminal outcome. Criminal Justice \& Behavior, 30, 688-708.

Cormier, C. (1994). Offender psycho-social assessment manual correctional model. Penetanguishene, Ontario, Canada: Ontario Mental Health Centre.

Crothers, L. M., \& Levinson, E. M. (2004). Assessment of bullying: A review of methods and instruments. Journal of Counseling \& Development, 82, 496-503.

Cunningham, N. J., \& Sandhu, D. S. (2000). A comprehensive approach to school-community violence prevention. Professional School Counseling, 4, 126-132.

D'Andrea, M. (2004). Comprehensive school-based violence prevention training: $A$ developmental-ecological training method. Journal of Counseling \& Development, 82, 277-286.

Douglas, K. S., Webster, C. D., Hart, S., Eaves, D., \& Ogloff, J. R. P. (2001). HCR-20 violence risk management companion guide. Burnaby, British Columbia, Canada: Simon Fraser University, Mental Health, Law, and Policy Institute.

Dubow, E., \& Reid, G. (1994). Risk and resource variables in children's aggressive behavior: A two-year longitudinal study. In L. Huesmann (Ed.), Aggressive behavior: Current perspectives (pp. 187-211). New York: Plenum Press.

Elinoff, M. J., Chafouleas, S. M., \& Sassu, K. A. (2004). Bullying: Considerations for defining and intervening in school settings. Psychology in the Schools, 41, 887-897.

Forth, A., Kosson, D. S., \& Hare, R. D. (2003). Hare Psychopathy Checklist: Youth Version. Minneapolis, MN: Pearson Assessments.

Frick, P. J. (2004). Developmental pathways to conduct disorder: Implications for serving youth who show severe aggressive and antisocial behavior. Psychology in the Schools, 41, 823-833.
Furlong, M., Morrison, G. M., Chung, A., Bates, M., \& Morrison, R. L. (1997). School violence. In Children's needs II (pp. 245-256). Bethesda, MD: National Association of School Psychologists.

Gacono, C. B., \& Hughes, T. L. (2004). Differentiating emotional disturbance from social maladjustment: Assessing psychopathology in aggressive youth. Psychology in the Schools, 4, 849-857.

Glasser, W. (2000). School violence from the perspective of William Glasser. Professional School Counseling, 4, 77-80.

Hare, R. (1999). Psychopathy as a risk factor for violence. Psychiatric Quarterly, 70, 181-196.

Hawkins, J., Herrenkohl, T., Farrington, D., Brewer, D., Catalano, R., \& Harachi, T. (1998). A review of predictors of youth violence. In R. Loeber \& D. Farrington (Eds.), Serious and violent juvenile offenders: Risk factors and successful interventions (pp. 106-146). Thousand Oaks, CA: Sage.

Hazler, R. J. (2000). When victims turn aggressors: Factors in the development of deadly school violence. Professional School Counseling, 4, 105-112.

Hazler, R. J., Hoover, J. H., \& Oliver, R. (1996). Student perceptions of victimization by bullies in schools. Journal of Humanistic Education and Development, 29, 143-150.

Hermann, M. A., \& Finn, A. (2002). An ethical and legal perspective on the role of school counselors in preventing violence in schools. Professional School Counseling, 6, 46-54.

Hernández, T. J., \& Seem, S. R. (2004). A safe school climate: A systematic approach and the school counselor. Professional School Counseling, 7, 256-262.

Hoge, R. D., \& Andrews, D. A. (2002). Youth Level of Service/Case Management Inventory: User's manual. Toronto, Ontario, Canada: Multi-Health Systems.

James, R., \& Gilliland, B. (2001). Crisis intervention strategies (4th ed.). Belmont, CA:Brooks/Cole.

Kumpfer, K. (1999). Factors and processes contributing to resilience: The resilience framework. In M. Glantz \& J. Johnson (Eds.), Resilience and development: Positive life adaptations. Longitudinal research in the social and behavioral sciences (pp. 179-224). New York: Kluwer Academic/Plenum.

Lapan, R. T., Gysbers, N. C., \& Petroski, G. F. (2001). Helping seventh graders be safe and successful: A statewide study of the impact of comprehensive guidance and counseling programs. Journal of Counseling \& Development, 79, 320-330.

Latzman, R. D., \& Swisher, R. R. (2005). The interactive relationship among adolescent violence, street violence, and depression. Journal of Community Psychology, 33, 355-371.

Levene, K. S., Augimeri, L. K., Pepler, D. J., Walsh, M. M., Webster, C. D., \& Koegl, C. J. (2001). Early assessment risk list for girls, version 1, consultation edition. Toronto, Ontario, Canada: Earlscourt Child and Family Center.

Makinson, L. S., \& Meyers, J. E. (2003). Wellness: An alternative paradigm for violence prevention. Journal of Humanistic Counseling, Education, and Development, 42, 165-177.

MCEachran, A. (2001). The predictive validity of the PCL-YV and the SAVRY in a population of adolescent offenders. Unpublished master's thesis, Simon Fraser University, Burnaby, British Columbia, Canada.

Moffitt, T. E. (1997). Adolescent-limited and life-coursepersisting offending: A complementary pair of developmental theories. In T. Thornberry (Ed.), Developmental theories of crime and delinquency ( $\mathrm{pp}$. 11-55). New Brunswick, NJ:Transaction Publishers. 
Newman-Carlson, D., \& Horne, A. M. (2004). Bully busters: A psychoeducational intervention for reducing bullying behavior in middle school students. Journal of Counseling \& Development, 82, 259-267.

Olympia, D., Farley, M., Christiansen, E., Pettersson, W. J., \& Clark, E. (2004). Social maladjustment and students with behavioral and emotional disorders: Revisiting basic assumptions and assessment issues. Psychology in the Schools, 41, 835-846.

Osher, D., \& Warger, C. (1998). Early warning, timely response: A guide to safe schools. Washington, DC:U.S. Department of Education.

Packman, W. L., Marlitt, B. A., Bongar, B., \& O'Connor Penuto, T. (2004). A comprehensive and concise assessment of suicide risk. Behavioral Sciences and the Law, 22, 667-680.

Reddy, M., Borum, R., Berglund, J., Vossekuil, B., Fein, R., \& Modzeleski, W. (2001). Evaluating risk for targeted violence in schools: Comparing risk assessment, threat assessment, and other approaches. Psychology in the Schools, 38, 157-172.

Riley, P. L. (2000). School violence prevention, intervention, and crisis response. Professional School Counseling, 4, 120-125.

Rollin, S. A., Kaiser-Ulrey, C., Potts, I., \& Creason, A. H. (2003). A school-based violence prevention model for at-risk eighth grade youth. Psychology in the Schools, 40, 403-416.

Sawyer, D., \& Cameron, J. K. (2001). Assessing violence potential: Protocol for dealing with high-risk student behaviors (5th ed.). First edition published in The Alberta Government Premiere's Task Force Report on Children at Risk: "Start Young, Start Now." Retrieved August 11, 2005, from http://www.cctatr.com/Protocol.pdf

Schaefer-Schiumo, K., \& Ginsberg, A. P. (2003). The effectiveness of the warning signs program in educating youth about violence prevention: A study with urban high school students. Professional School Counseling, 7, 1-7.

Sherman, L. W., Gottfredson, D., MacKenzie, D., Eck, J., Reuter, P., \& Bushway, S. (1997). Preventing crime: What works, what doesn't, what's promising. Washington, DC: U.S.

Department of Justice, Office of Justice Programs.
Simons, K. Paternite, C., \& Shore, C. (2001). Quality of parent/adolescent attachment and aggression in young adolescents. Journal of Early Adolescence, 21, 182-203.

Smith, D. C., \& Sandhu, D. S. (2004). Toward a positive perspective on violence prevention in schools: Building connections. Journal of Counseling \& Development, 82, 287-293.

Stanley, P. H., Juhnke, G. A., \& Purkey, W. W. (2004). Using an invitational theory of practice to create safe and successful schools. Journal of Counseling \& Development, $82,302-309$.

Stevens, L., Lynm, C., \& Glass, R. (2001). Youth violence in schools. Journal of the American Medical Association, 286, 2695-2702.

U.S. Preventive Services Task Force. (2004). Screening for suicide risk: Recommendations and rationale [Electronic version]. American Family Physician, 70, 2187-2190.

Vossekuil, B., Reddy, M., Fein, R., Borum, R., \& Modzeleski, W. (2000). U.S.S.S. safe school initiative: An interim report on the prevention of targeted violence in schools. Washington, DC:U.S. Secret Service, National Threat Assessment Center.

Webster, C. D., Douglas, K. S., Eaves, D., \& Hart, S. D. (1997). HCR20: Assessing risk for violence, version 2. Burnaby, British Columbia, Canada: Simon Fraser University, Mental Health, Law, and Policy Institute.

Wingate, L. R., Joiner, T. E., Walker, R. L., Rudd, M. D., \& Jobes, D. A. (2004). Empirically informed approaches to topics in suicide risk assessment. Behavioral Sciences and the Law, 22,651-655.

\section{Earn CEUs for reading this article. Visit www.schoolcounselor.org, and click on Professional School Counseling to learn how.}

